\title{
AMBIENTES VIRTUAIS DE APRENDIZAGEM: IMPLICAÇÕES EPISTEMOLÓGICAS'
}

Vera Menezes de 0. Paiva*

RESUMO: Este texto apresenta algumas visões epistemológicas - objetivismo, subjetivismo e experiencialismo -, em uma tentativa de compreender os conceitos de conhecimento e de aprendizagem subjacentes à construção de ambientes virtuais de aprendizagem. Apresenta, também, uma descrição de três plataformas de aprendizagem gratuitas - AulaNet, Moodle e TeleEduc - e enfatiza que outras ferramentas do internet pode ser adicionadas a esses ambientes educacionais virtuais, de forma a propiciar mais experiências de aprendizagem. Finalmente, conclui que o ambiente virtual retira os professores do palco da aprendizagem, pois eles também podem aprender com os alunos.

Palavras-chave: Epistemologia; Ambientes Virtuais de Aprendizagem; Redes Colaborativas.

\section{VIRTUAL LEARNING ENVIRONMENTS: EPISTEMOLOGICAL IMPLICATIONS}

ABSTRACT: This text presents some epistemological views - objectivism, subjectivism and experientialism - aiming at understanding the concepts of knowledge and learning which underlay the construction of virtual learning environments. It also presents a description of three free learning software - AulaNet, Moodle and TeleEduc - and emphasizes that other internet tools can be added to those virtual educational environments in order to offer more learning experiences. Finally, it concludes that learning environments remove teachers from the learning stage as they can also learn with the students.

Keywords: Epistemology; Virtual Learning Environments; Collaborative Network.

* Doutora em Linguística e Filologia pela Universidade Federal do Rio de Janeiro (UFRJ); Professora titular da Universidade Federal de Minas Gerais (UFMG) e Pesquisadora do Conselho Nacional de Desenvolvimento Científico e Tecnológico (CNPq). E-mail: vlmop@veramenezes.com 


\section{Visões epistemológicas}

Epistemologia ou teoria do conhecimento, segundo Harlow e Johnson (1998, p. 15), refere-se "ao modo como a mente processa e forma crenças sobre objetos e eventos ao nosso redor"'. Os autores oferecerem três visões epistemológicas que eles denominam de (1) ingênua, (2) piagetiana (3) e wittgensteiniana.

A visão ingênua é representada pela mente como recipiente, ou seja, a mente é entendida como local de armazenamento de informações. Nessa visão, segundo os autores, "o conhecimento é visto como uma coleção de verdades enquanto a mente é vista como um museu metafórico para essas verdades” (p. 15). Na visão piagetiana, os esquemas mentais são construídos a partir da experiência do indivíduo com o ambiente e o conhecimento não é entendido como cópia do mundo, mas como reconstrução subjetiva ou individual. Para Wittgenstein, o conhecimento é construído pela participação do sujeito em sua cultura. Na opinião de Harlow e Johnson (1998, p. 16), Wittgenstein distingue aquisição de conhecimento de aprendizagem. Aquisição seria um processo inconsciente e aprendizagem, um processo intencional.

Posto de outra forma, poderíamos dizer que as três visões apresentadas por Harlow e Johnson (1998) são equivalentes aos "mitos" descritos por Lakoff e Johnson (1980). Para eles, mitos são formas de compreender a experiência e dar sentido à nossa vida. Eles consideram que dois mitos governam a ciência - o objetivismo e o subjetivismo - e fazem opção por um terceiro, o experiencialismo. O objetivismo corresponde à visão ingênua, o subjetivismo encontra paralelo no construtivismo e a produção de conhecimento como fruto do conjunto de nossas experiências descreve a essência do experiencialismo.

As práticas pedagógicas são determinadas pelas concepções epistemológicas e pelas metáforas que essas concepções geram. Segundo Verneil e Berge (2000, p. 15), “[O]s modelos objetivistas, geralmente, descrevem a interação entre o professor e o aluno e entre o aluno e o conteúdo, mas dá pouca atenção à interação em pares". Segundo esses mesmos autores, na visão objetivista, a mente é vista como um container e, na construtivista, como um processador, ou seja, o mundo pessoal de cada aluno é construído em sua mente e são essas construções pessoais que definem as realidades pessoais. Eu acrescentaria que, na visão experencial, 
a aprendizagem emerge das experiências vividas em práticas sociais. $\mathrm{O}$ Quadro 1 apresenta uma comparação entre essas três visões epistemológicas.

QUADRO 1. Comparação de três diferentes visões epistemológicas.

\begin{tabular}{|c|c|c|}
\hline Objetivismo & Subjetivismo & Experiencialismo \\
\hline 0 conhecimento é objetivo & $\begin{array}{l}0 \text { conhecimento é subjetivo e } \\
\text { individual }\end{array}$ & $\begin{array}{l}0 \text { conhecimento é dinâmico e } \\
\text { social }\end{array}$ \\
\hline $\begin{array}{l}\text { Metáfora do recipiente, } \\
\text { da biblioteca, do museu } \\
\text { Inteligência mensurável }\end{array}$ & $\begin{array}{l}\text { Metáfora da construção, do lego } \\
\text { Inteligências múltiplas }\end{array}$ & $\begin{array}{l}\text { Metáfora da rede, da teia } \\
\text { Inteligência coletiva }\end{array}$ \\
\hline $\begin{array}{l}0 \text { conhecimento é adquirido } \\
\text { por transferência }\end{array}$ & $\begin{array}{l}0 \text { conhecimento é adquirido pela } \\
\text { construção }\end{array}$ & $\begin{array}{l}0 \text { conhecimento emerge da } \\
\text { participação }\end{array}$ \\
\hline Conhecimento é produto & Conhecimento é processo & Conhecimento é emergência \\
\hline Aprendiz é receptor & Aprendiz é construtor & Aprendiz é experimentador \\
\hline $\begin{array}{c}0 \text { conhecimento se acumula } \\
\text { e se sedimenta }\end{array}$ & $\begin{array}{c}0 \text { conhecimento cresce e se } \\
\text { desenvolve }\end{array}$ & $\begin{array}{l}0 \text { conhecimento muda } \\
\text { constantemente }\end{array}$ \\
\hline Automatização & Computação mental & Comunidades de prática \\
\hline
\end{tabular}

Como podemos depreender do Quadro 1, no experiencialismo, o conhecimento passa a ser visto como algo dinâmico, em constante processo de mudança, e que emerge das experiências em uma rede social colaborativa. O conhecimento não é algo dado, que se encontra no ambiente, e nem é visto como mera construção subjetiva, mas é fruto das experiências em uma comunidade de prática que se caracterizam, segundo Wenger (1998), pelo compartilhamento de interesses entre seus membros, pelo repertório compartilhado e pelo empreendimento conjunto.

A metáfora da aquisição, fundamentada na visão epistemológica ingênua da objetividade, vem cedendo espaço para a metáfora da participação ${ }^{3}$, como proposta por Sfard (1998). Segundo ela, “[d]esde o despontar da civilização, a aprendizagem é concebida como aquisição" (p. 5), e cita como exemplo a definição do dicionário de inglês Collins, que define aprendizagem como "O ato de ganhar conhecimento". No dicionário Aurélio, aprender é definido como "tomar conhecimento de". Em ambos os verbetes, predomina a ideia e de que o conhecimento é algo externo ao aprendiz, algo que se encontra disponível no ambiente. A ideia de aprendizagem como aquisição de conhecimento está presente em palavras e 
expressões como acúmulo, transferência, transmissão, apropriação, crescimento e desenvolvimento de conhecimento.

Com a predominância da teoria sociocultural, nos dias de hoje, e de novos conceitos - comunidades de prática (WENGER, 1998); inteligência coletiva (LÉVY, 1998); aprendizagem distribuída, inteligência distribuída ou cognição distribuída (ver BELL; WINN, 2000); cognição situada (LAVE, 1991); e ecologias de aprendizagem (ver HILL; WILSON; WATSON, 2004) -, uma nova metáfora ganha destaque: a da participação. Como salienta Sfard (1998), com essa nova metáfora, a aprendizagem passa a ser vista como "um processo de tornar-se membro de uma determinada comunidade" (p. 6) e evoca as ideias de "se estar junto, de solidariedade, e de colaboração" (p. 8).

Na próxima seção, discuto as implicações epistemológicas para os ambientes de aprendizagem.

\section{Ambientes de aprendizagem}

A sala de aula tradicional guarda bastante identidade com a visão objetivista da aprendizagem e a metáfora da aquisição, como podemos inferir da descrição feita por Matte (2009):

Toda sala de aula possui frente e fundos em sua organização interna. Enquanto o professor é um ator ocupando um papel actancial de destinador, os alunos são vários atores ocupando um papel actancial de destinatário. A posição frontal do professor garante um foco de atenção privilegiado: porque todos olham pra ele e porque seu espaço de atuação é maior e mais maleável que o de cada aluno. A posição sentada dos alunos contrapõe-se à sua liberdade de sentar, levantar, andar. Quanto maior o número de alunos por metro quadrado, maior essa diferença, pois menor a liberdade dos alunos. Além disso, o professor dispõe de recursos que tornam visível sua atuação sobre toda a turma, enquanto os alunos somente podem realizar registros individuais e pequenas intervenções orais.

Nessa descrição, temos a materialização da metáfora da transmissão de conhecimento, em que o professor/destinador/emissor detém o conhecimento e o envia ao aluno/destinatário/receptor. Essa visão de aprendizagem privilegia o modelo de aula expositiva, com pouco espaço para a exploração do conteúdo em estudo. Como ressalta Thomas (2009, 
p. 2), a sala de aula tradicional não oferece os propiciamentos (affordances) que possibilitam uma aprendizagem mais engajada. Isso é parcialmente verdade, pois a sala de aula pode ser também o local de incentivo a experiências de aprendizagem inovadoras e bem-sucedidas.

Com o advento da internet, surgiram aplicações, na web, para gerenciamento de atividades educacionais guiadas pela metáfora da participação que podem contribuir para a aprendizagem colaborativa. Os ambientes virtuais de aprendizagem oferecem espaços virtuais ideais para que os alunos possam se reunir, compartilhar, colaborar e aprender juntos. Vale ressaltar que, no Brasil, esses ambientes virtuais, ou plataformas para educação on-line, ficaram consagrados com o nome de ambientes virtuais de aprendizagem (de agora em diante AVAs), mas, além desta, receberam nomes e siglas diferentes, em inglês, tais como ambientes integrados de aprendizagem (Integrated Distributed Learning Environments - IDLE); sistema de gerenciamento de aprendizagem (Learning Management System $L M S$ ); e espaços virtuais de aprendizagem (Virtual Learning Spaces VLE).

Esses aplicativos, geralmente, oferecem uma interface gráfica e algumas ferramentas, tais como: ferramentas de comunicação assíncrona (fórum, e-mail, blog, mural) e síncrona (chat); ferramentas de avaliação e de construção coletiva (testes, trabalhos, wikis, glossários; ferramentas de instrução (textos, atividades, livros, vídeos); ferramentas de pesquisa de opinião (enquete, questionários); e ferramentas de administração (perfil do aluno, cadastro, emissão de senha, criação de grupos, banco de dados, configurações, diários de classe, geração de controle de frequência e geração de relatórios, gráficos e estatísticas de participação).

$\mathrm{Na}$ década de 1990, com a popularização da internet, várias ferramentas foram desenvolvidas e comercializadas. Em 1998, McGreal (1998, p. 28-29) listava 23 AVAs: Forum, Virtual-U, Learning Space, Learning Server, Symposium, Web-CT, FirstClass, TopClass, ClassNet, CourseSite Generator, Flax, IBT Author, Mallard, Oracle Learning Architecture, Peebblesoft, Polis, Serf, ShareKnowledge, Socrates, The Learning Manager, ToolBook II Librarian, Web Course in a Box, e Zebu. Essa lista não inclui o Blackboard, que também fez muito sucesso no Brasil, ao lado do WebCT, do LearningSpace e do FirstClass.

Como esses aplicativos eram muito caros e seus preços variavam em função da quantidade de alunos, grupos de pesquisa começaram a 
desenvolver plataformas gratuitas. Todos eles procuram se organizar em torno da metáfora da participação. No Brasil, destacam-se o AulaNet e o TeleEduc, apesar de existirem outros, como o E-proinfo, o ROODA, o Eureka e o Virtus. Os AVAs pagos estão, atualmente, sofrendo uma forte concorrência, no mundo inteiro, de outro AVA gratuito - o Moodle (Object-Oriented Dynamic Learning Environment), cujo desenvolvimento conta com o apoio de uma comunidade global. Além dos AVAs, outros aplicativos na web, as chamadas redes sociais, como, por exemplo, Second Life (PHAM, B. et al., 2008), Facebook (IDRIS; WANG, 2009), Ning (LARA; NAVAL, 2009) e até o Orkut, também têm sido utilizados como espaço de aprendizagem.

A seguir, apresento descrições do AulaNet, do Moodle e do TeleEduc, em função de sua ampla utilização no Brasil.

\subsection{AulaNet}

No Brasil, o primeiro AVA gratuito de sucesso foi o AulaNet (Figura 1). Em desenvolvimento desde 1997, o AulaNet é distribuído gratuitamente pelo Laboratório de Engenharia de Software da PUC-Rio. Seus desenvolvedores afirmam que o AulaNet "se baseia nas relações de trabalho cooperativo que se manifestam nas interações dos aprendizes com seus instrutores, com outros aprendizes e com os conteúdos didáticos" (GEROSA; CUNHA; FUKS; LUCENA, 2001, p. 1). Eles acrescentam que o ambiente é organizado de forma que os aprendizes possam aprender em grupo, compartilhando ideias e cooperando com os colegas. A plataforma oferece agenda, quadro de avisos, serviço de e-mail, lista de discussão, fórum, chat e ferramenta de videoconferência (CU-SeeMe). É possível inserir transparências, apresentações gravadas, textos de aula, livros-texto e bibliografia, e a interface do aluno permite que sejam abertas várias telas ao mesmo tempo, como, por exemplo, um vídeo, uma transparência e um texto de aula. 
FIGURA 1 - Página inicial do AulaNet.

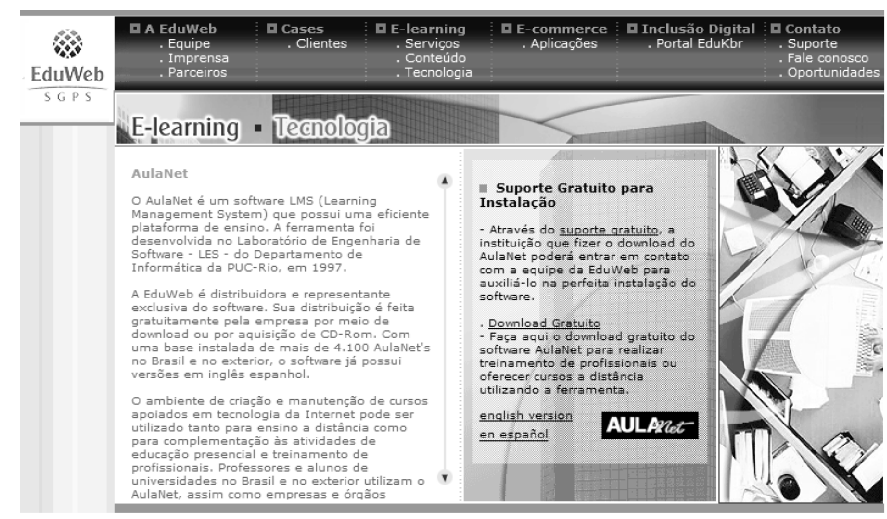

Fonte: http://www.eduweb.com.br/elearning_tecnologia.asp

\subsection{Moodle}

O Moodle (Modular Object-Oriented Dynamic Learning Environment) é uma plataforma que foi desenvolvida, como software livre, por Martin Dougiama (http://dougiamas.com/), um ex-gerente do Sistema WebCT, e conta com colaboradores no mundo inteiro, trabalhando no seu aprimoramento. Esse AVA é utilizado não só para a oferta de cursos, mas também para grupos de pesquisa e eventos.

Segundo informações da página em português do Moodle na web (http://docs.moodle.org/pt_br/), esse AVA “já foi traduzido para mais de 70 línguas" e há centenas de milhares de sites que usam essa plataforma. Nessa mesma página, eles explicitam as bases epistemológicas da construção do ambiente:

O Moodle é um software para gestão da aprendizagem e de trabalho colaborativo, permitindo a criação de cursos online, páginas de disciplinas e de grupos de trabalho. Está em desenvolvimento constante, tendo como filosofia uma abordagem social construccionista da educação.

Esse software funciona em qualquer sistema operacional que suporte a linguagem PHP e é construído em módulos, o que permite adicionar, configurar ou remover funcionalidades. São as seguintes as ferramentas encontradas no Moodle: página para perfil dos alunos, inserção de avatares, fóruns, calendário, gestão de conteúdo, página de perguntas mais 
frequentes, criação de grupos, questionários e pesquisas, blogs, wikis, bancos de dados, sondagens, chat, glossários, ferramenta para construção de testes, avaliação em par e diários. Além disso, há as ferramentas administrativas, que permitem configurar o AVA, ativar edição, designar funções, atribuir notas, criar grupos, fazer backup, restaurar, importar, reconfigurar e emitir relatórios. Na Figura 2, vemos a página inicial da disciplina de Leitura "Inglês Instrumental II", ministrada no Moodle, no segundo semestre de 2009, para 891 estudantes da graduação e funcionários da UFMG, nos campi de Belo Horizonte e de Montes Claros.

FIGURA 2 - Página da disciplina de Leitura Instrumental II - 2009/2/UFMG.

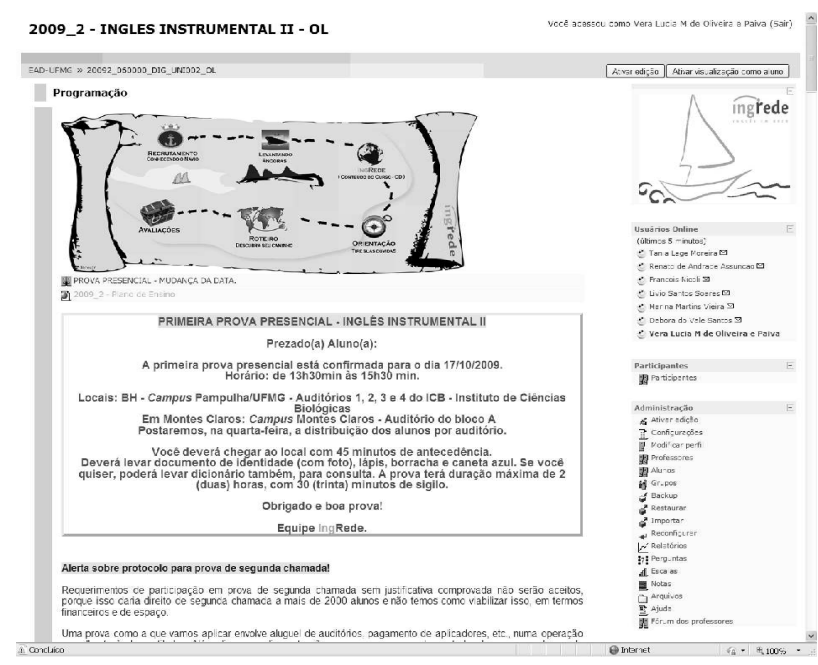

Fonte: http://sureco.grude.ufmg.br/moodle16/course/view.php?id= 55217

Na UFMG, para cada disciplina ofertada na graduação e na pósgraduação, é criada uma página no Moodle, como suporte para as disciplinas presenciais ou a distância.

\subsection{TelEduc}

Outro AVA bastante utilizado no Brasil é o TelEduc, desenvolvido no Núcleo de Informática Aplicada à Educação (NIED) da Universidade Estadual de Campinas. Segundo informação disponível em sua página inicial na web (http://www.TeleEduc.org.br), o TeleEduc "foi concebido tendo como alvo o processo de formação de professores para 
informática educativa, baseado na metodologia de formação contextualizada". Seus idealizadores ressaltam a importância da interação entre os participantes:

A intensa comunicação entre os participantes do curso e ampla visibilidade dos trabalhos desenvolvidos também são pontos importantes, por isso foi desenvolvido um amplo conjunto de ferramentas de comunicação como o Correio Eletrônico, Grupos de Discussão, Mural, Portfólio, Diário de Bordo, Bate-Papo etc., além de ferramentas de consulta às informações geradas em um curso como a ferramenta Intermap, Acessos, etc.

Na UFMG, o TeleEduc está hospedado no Núcleo de Ensino a Distância da Escola de Engenharia, sob o gerenciamento do departamento de Engenharia Elétrica. É lá que estão hospedadas as dez Oficinas de Leitura e Produção de Textos, ofertadas em 2009, sob a coordenação da Prof $^{a}$ Carla Coscarelli, e onde também hospedo as disciplinas que ministro na graduação e na pós-graduação. A Figura 3 reproduz a página inicial da disciplina - "A mediação das novas tecnologias e a pesquisa em Linguística Aplicada" - ofertada para mestrandos e doutorandos da UFMG e da UFRJ e ministrada, em conjunto, pela autora deste artigo e pela Profa. Kátia Tavares, da UFRJ.

FIGURA 3 - Página da disciplina

"A mediação das novas tecnologias e a pesquisa em Linguística Aplicada".

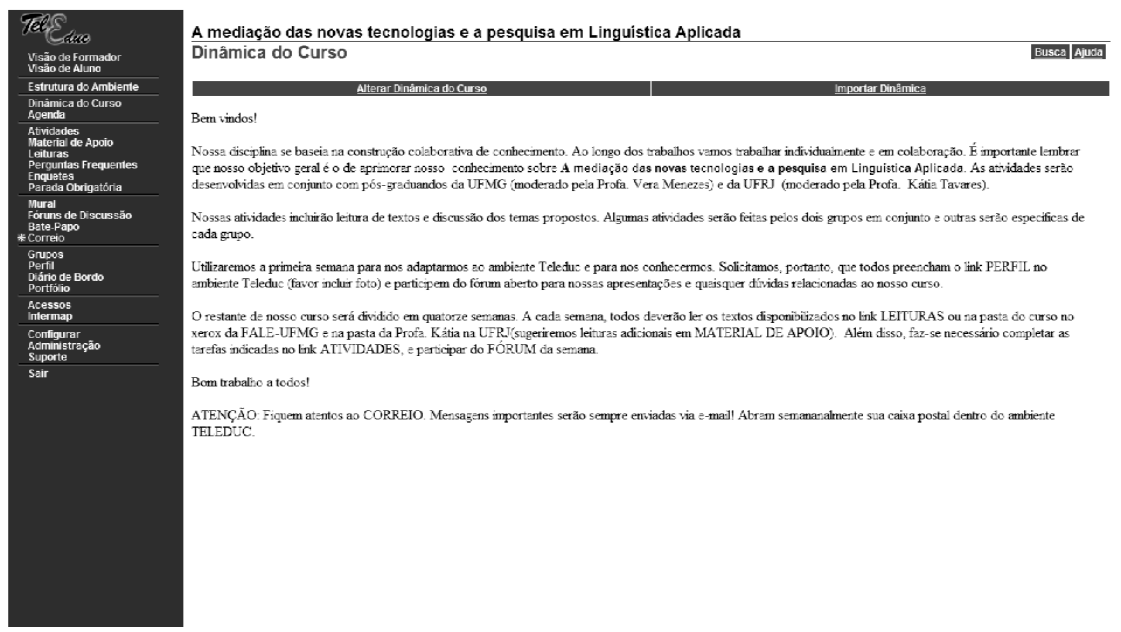

Fonte: http://teleduc.ead.cpdee.ufmg.br/cursos/aplic/index.php?cod_curso $=567$ 
Esse AVA oferece três ferramentas que são de uso obrigatório e ficam visíveis para todos (professores e alunos). São elas: a Estrutura do Ambiente, com a descrição de cada parte do ambiente e das ferramentas; a Dinâmica do Curso, com informações sobre a metodologia e a organização do curso; e a Agenda, que é a página de entrada do ambiente, em que o professor insere a programação das atividades. As outras ferramentas são optativas para o professor, que escolhe o que quiser para compor sua disciplina. A seguir, apresento as demais ferramentas, conforme descrição na página Estrutura do Ambiente. São elas:

Avaliações: onde podemos listar as avaliações feitas ou em andamento no curso, suas datas de início de término, seus objetivos e critérios de avaliação, bem como as notas dos alunos e os comentários dos formadores sobre elas;

Atividades: Atividades em que podemos especificar os detalhes de cada atividade e o período de realização;

Material de Apoio: onde reunimos informações úteis para os alunos; Leituras: em que podemos listar sugestões de revistas, jornais, endereços na web, etc.;

Perguntas frequentes (FAOs): local para reunir as dúvidas mais frequentes e as respectivas respostas;

Enquetes: uma ferramenta de sondagem de opinião dos alunos sobre qualquer assunto;

Exercícios: uma ferramenta para criação/edição e gerenciamento de exercícios com questões dissertativas, de múltipla escolha, de associar colunas e de verdadeiro ou falso;

Parada Obrigatória: ferramenta para inserção de materiais que visam a desencadear reflexões e discussões entre os participantes, ao longo do curso;

Mural: espaço reservado para que todos os participantes possam disponibilizar informações consideradas relevantes para o contexto do curso;

Fórum de Discussão: uma página que reúne os tópicos que estão em discussão em determinado momento do curso.

Bate-papo: onde é possível realizar uma conversa em tempo real entre os alunos do curso e os formadores ou entre um grupo de alunos, ficando as interações gravadas para posterior acesso, se necessário;

Correio: um sistema de correio eletrônico interno ao ambiente. Só os formadores podem enviar mensagens para fora do ambiente. 
Grupos: ferramenta para criação de grupos (pelo professor ou pelos alunos), para facilitar a distribuição e/ou o desenvolvimento de tarefas colaborativas;

Perfil: um espaço reservado para que cada participante do curso possa se apresentar aos demais, descrevendo suas principais características, além de permitir a edição de dados pessoais;

Diário de Bordo: espaço reservado para o aluno registrar suas experiências ao longo do curso: sucessos, dificuldades, dúvidas, anseios visando a proporcionar meios que desencadeiem um processo reflexivo a respeito do seu processo de aprendizagem. As anotações pessoais podem ser compartilhadas ou não com os demais participantes do curso. Em caso positivo, podem ser lidas e/ou comentadas por outras pessoas, servindo, também, como outro meio de comunicação; e

Portfólio: espaço onde os participantes do curso podem armazenar, individualmente ou em grupo, atividades desenvolvidas durante o curso. Esses dados podem ser particulares, compartilhados apenas com os formadores ou compartilhados com todos os participantes do curso. Cada participante pode ver os demais portfólios (se compartilhados com todos) e comentá-los.

Além das ferramentas de ensino e aprendizagem, existem as de gerenciamento de acesso e frequência. A ferramenta Acesso permite acompanhar a frequência de acesso dos usuários ao curso e às suas ferramentas. O Intermap permite a visualização da interação dos participantes do curso nas ferramentas Correio, Fóruns de Discussão e Bate-Papo. A ferramenta Configurar permite alterar configurações pessoais no ambiente, tais como: dados pessoais, login, senha, idioma e notificação de novidades. Finalmente, a ferramenta Administração, de uso exclusivo do professor, permite a ele visualizar dados e alterá-los, escolher as ferramentas do curso, inscrever alunos e formadores e gerenciar as inscrições e o envio de senhas. Há, ainda, um link para Suporte, que permite contato, por email, com o administrador TeleEduc.

\subsection{Ampliando as possibilidades dos AVAs}

Apesar da extensa gama de ferramentas que encontramos nos AVAs, novas tecnologias são desenvolvidas em ritmo acelerado e o professor pode, sempre, complementar sua sala de aula virtual. Trago, como exemplos, algumas ferramentas que foram acrescentadas a uma disciplina 
oferecida, em conjunto, por mim e pela Prof ${ }^{a}$ Kátia Tavares, da UFRJ, para mestrandos e doutorandos do Programas de Pós-Graduação em Estudos Linguísticos da UFMG e do Programa Interdisciplinar de PósGraduação em Linguística Aplicada da UFRJ, utilizando a plataforma TelEduc. Nessa disciplina, agregamos o uso de Walwisher, DropAvideo, outras páginas na web (textos, revistas na web, portal da CAPES), CmapTools e três ferramentas diferentes para produção de textos de forma colaborativa: GoogleDocs, Writeboard e Zoho wiki.

$\mathrm{Na}$ Figura 5, temos a imagem de um mural eletrônico, o Walwisher (http://www.wallwisher.com), no qual os participantes deixaram alguns comentários sobre suas leituras sobre Cognição Situada. Como podemos ver, ao clicarmos no link dentro do TeleEduc, ele abre uma página, como se o participante ainda estivesse dentro da plataforma, dando a ilusão de unicidade espacial e de agregação física da nova ferramenta:

Figura 5 - Exemplo de uso do Wallwisher.

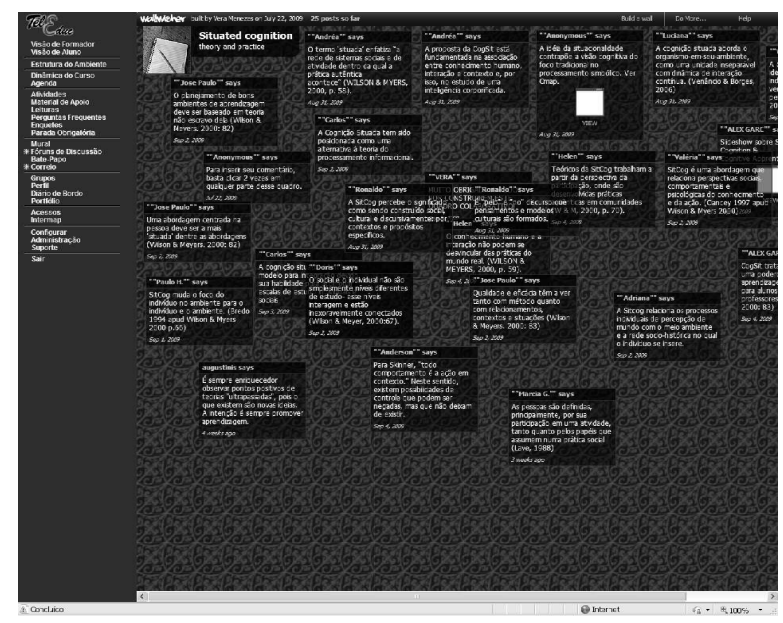

Fonte: http://www.wallwisher.com/wall/sitcognition

A Figura 6 mostra a coleção de vídeos sobre teoria da atividade, selecionados pela Prof ${ }^{a}$ Kátia Tavares e reunidos no DropAvideo (http://dropavideo.com). A tarefa dos alunos era visitar esse repositório de vídeos, escolher pelo menos dois vídeos e, após assistir, deixar comentários no próprio site do DropAvideo. 
Figura 6 - Página do DropAVideo da Profa. Kátia Tavares.

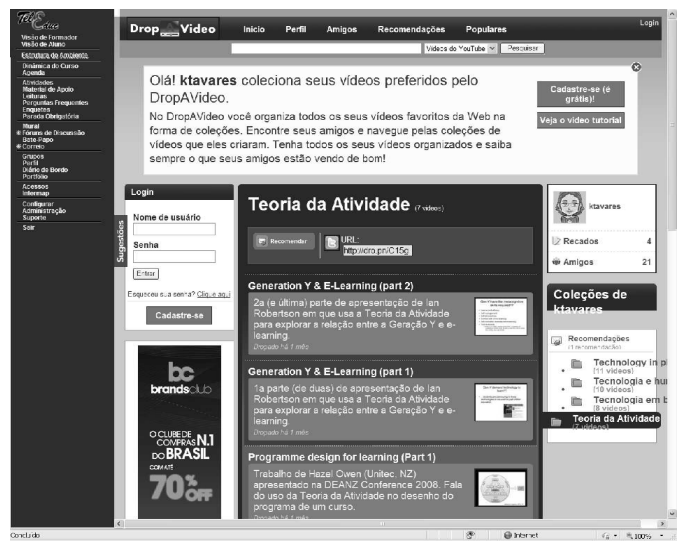

Fonte: http://dropavideo.com/user/ktavares/

Outra ferramenta utilizada foi o CmapTools (http://cmap.ihmc.us/ conceptmap.html), ferramenta gratuita para construção de mapas conceituais. Foi pedido aos alunos que fizessem o mapa conceitual de um texto de Barab e Duffy (2000). Um dos mapas feitos pelos alunos é mostrado a seguir.

Figura 7 - Mapa conceitual de um dos alunos da disciplina.

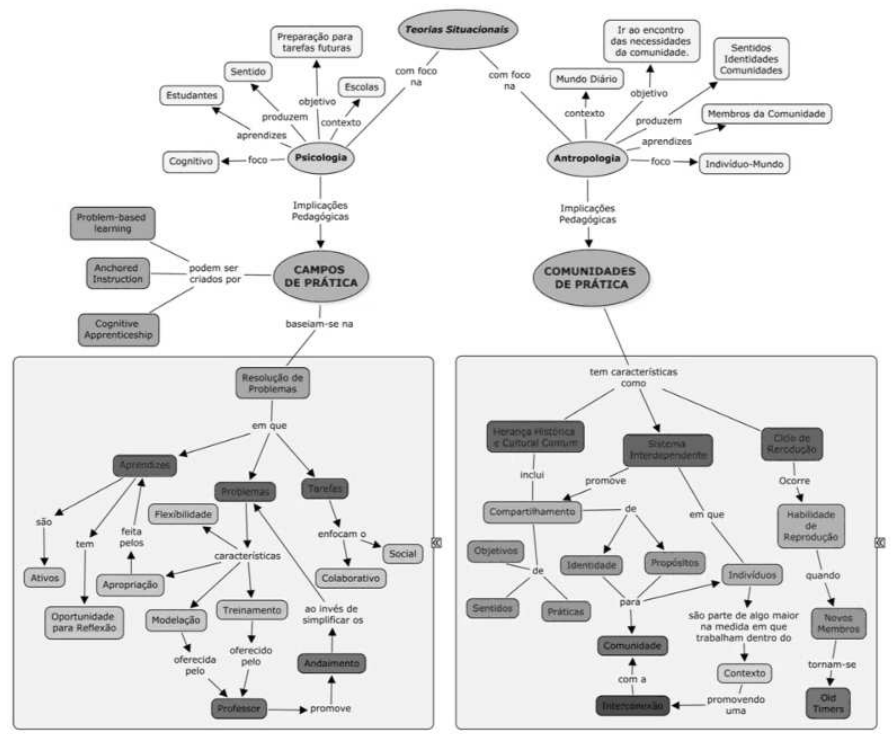

Fonte: Material arquivado no curso http://teleduc.ead.cpdee.ufmg.br/cursos/aplic/index.php?cod_curso=567 
O material do curso foi composto por textos das próprias professoras e por capítulos de livros e artigos de revistas de diversos autores previamente selecionados, além de outras referências bibliográficas que foram trazidas pelos alunos, ao longo do curso, ora como demanda das atividades e ora como colaboração espontânea.

No TeleEduc, o aluno pode postar um documento e ele ou seus colegas podem editá-lo. Dados identificando o dia, a hora e o autor de edição são registrados pela ferramenta, mas não há recurso para produção de texto colaborativo em formato de wiki. Para suprir essa ausência, recorremos ao GoogleDocs (http://docs.google.com), ao Writeboard (http://writeboard.com) e ao Zoho wiki (http://wiki.zoho.com). Nas Figuras 8 e 9, podemos ver a reprodução das páginas iniciais do Writeboard e do Zoho wiki, respectivamente, enquadradas dentro da página do TeleEduc.

Figura 8 - Página do Writeboard vista pelos alunos no TelEduc.

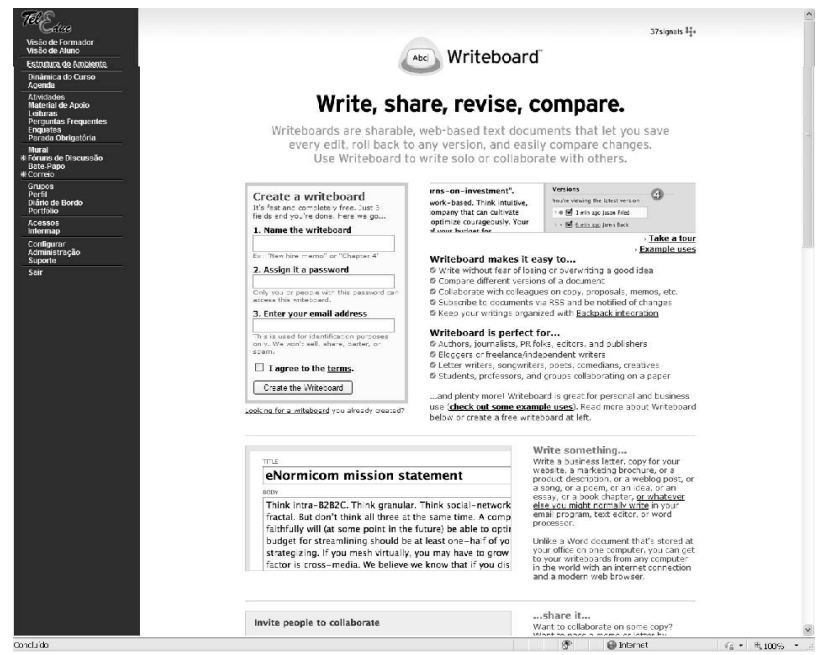

Fonte: página do curso http://teleduc.ead.cpdee.ufmg.br/cursos/aplic/index.php?cod_curso $=567$ 
Figura 9 - Página do Zoho wiki vista pelos alunos no TelEduc.

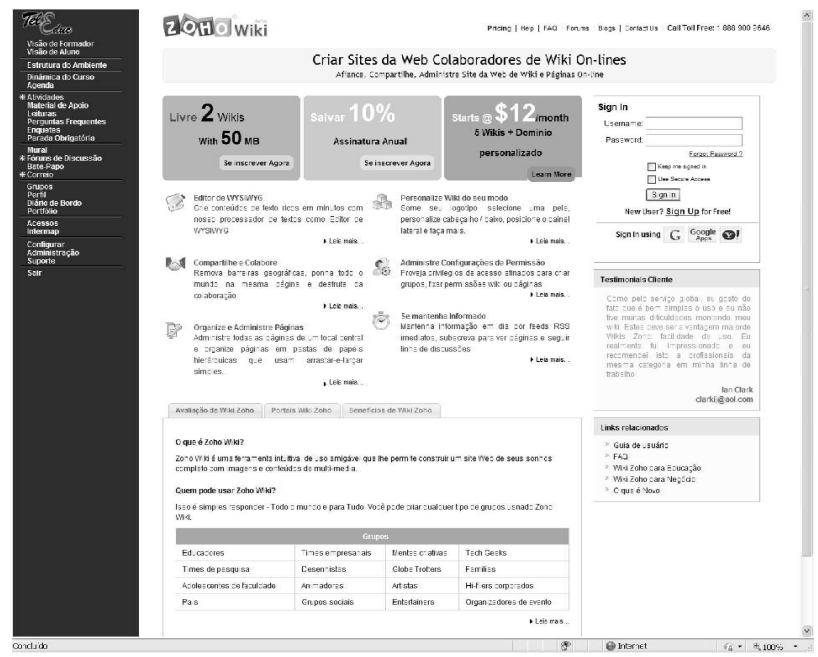

Fonte: página do curso http://teleduc.ead.cpdee.ufmg.br/cursos/aplic/index.php?cod_curso $=567$

Nessa disciplina, ministrada a quatro mãos, os participantes tiveram oportunidade de tirar proveito de várias ferramentas. Eles usaram o correio eletrônico para tirar dúvidas e fazer comunicados; postaram sugestões de leituras e de sites interessantes no mural. Construíram um portfólio individual com resenhas, mapas conceituais e reflexões sobre os textos lidos e um portfólio do grupo, com os textos construídos a várias mãos. Eles participaram de fóruns sobre temas diferentes e muitos deles ignoraram a participação das professoras no fórum, engajando-se em outras discussões, atraídos por tópicos iniciados por um colega. Chamaram especial atenção as propostas de alguns alunos de substituição de algumas ferramentas por outras similares. Por exemplo: na semana em que propusemos o uso do CmapTools, um participante sugeriu uma outra opção, o bubbl.us (https://bubbl.us/beta). Os participantes também sugeriram quatro alternativas para a ferramenta de criação de wikis - Etherpad, Zoho wiki, ThinkFree e Pbworks -, o que acabou gerando uma enquete para escolha da ferramenta preferida. A escolhida foi a Zoho wiki. 


\section{Conclusão}

As descrições fornecidas pelos três AVAs,aqui descritos explicitam uma opção epistemológica que privilegia a noção de conhecimento como construção e colaboração, mas o que determina a orientação epistemológica de um curso não é o AVA, mas o design de cada curso. Sendo assim, podem conviver nesses AVAs atividades que focam apenas a transmissão e o armazenamento de informação, as que proporcionam a construção subjetiva do conhecimento ou, ainda, as que incentivam a emergência de experiências colaborativas. Cada vez mais, surgem experiências inovadoras que rompem com o mito objetivista e buscam uma mudança de paradigma, proporcionando ao aprendiz uma diversidade de ferramentas de comunicação e de experiências de aprendizagem.

O aprendiz motivado, quando encontra oportunidades mais desafiadoras, acaba passando mais tempo envolvido com a experiência de aprender. Os alunos detêm mais controle sobre as tarefas, podendo ler e reler sua participação antes da postagem, o que a torna mais elaborada. Durante o tempo em que o material fica disponível, os alunos podem ler e reler as participações do professor e dos colegas quantas vezes quiserem e explorar mais os assuntos que lhes interessam. Não sou favorável, no entanto, à demonização da sala de aula tradicional, pois acredito que boas e más experiências podem acontecer em qualquer ambiente.

Os AVAs configurados para proporcionar experiências em redes colaborativas retiram o professor da frente da sala de aula e o deslocam para os bastidores ou para junto dos alunos. Isso me faz lembrar as três feridas narcísicas sofridas pela humanidade, segundo Freud: a descoberta de Copérnico de que a Terra não é o centro do universo; a afirmação de Darwin de que o Homem não tem linhagem divina; e ouvir, do próprio Freud, que o Inconsciente existe e que ele impede o controle de nossa mente. Há especulações sobre qual seria a quarta ferida narcísica. Uma delas seria a descoberta de uma civilização que tirasse do Homem a condição de ser superior.

Parafraseando Freud, eu diria que o professor também tem suas feridas narcísicas: perceber que não está mais no centro do processo pedagógico; ter consciência de que não há como dominar e transmitir todo o conhecimento de sua área; e descobrir que não tem domínio sobre o aluno, que aprende apesar do professor. A quarta grande ferida narcísica seria a descoberta de que o professor também aprende com seus alunos. 


\section{Referências}

BARAB, S.A.; DUFFY, T.M. From practice fields to communities of practice. In: JONASSEN, D.H; LAND, S.M. Theoretical foundations of learning environment. Mahwah, NJ; London: Lawrence Erlbaum, 2000. p. 25-55.

BELL, P.;WINN, W. Distributed cognitions, by nature and by design. In: JONASSEN, D.H.; LAND, S.M. (Eds.) Theoretical foundations of learning environments. Mahwah: Lawrence Erlbaum, 2000. p. 123-145.

GEROSA, M.A.; CUNHA, L.M.; FUKS, H.; LUCENA, C.J.P. Um groupware baseado no ambiente AulaNet desenvolvido com componentes. Workshop de Desenvolvimento baseado em componentes, Maringá-PR, 21-22 Junho 2001. Disponível em: <http://groupware.les.inf.puc-rio.br/groupware/publicacoes/WBDC.pdf>. Acesso em: 01 out. 2009.

HARLOW, S.D.; JOHNSON, D. An epistemology of technology. Educational Technology Review, n. 9, p. 15-20, Spring/Summer 1998.

HILL, S. B; WILSON, S; WATSON, K. Learning ecology. A new approach to learning and transforming ecological consciousness. In: O'SULLIVAN, W.; TAYLOR, M. (Eds.) M. Learning Toward an Ecological Consciousness: Selected Transformative Practices. New York: Palgrave Macmillan, 2004. p. 47-64.

IDRIS, Y.; WANG, Q. Affordances of Facebook for learning. International Journal of Continuing Engineering Education and Life Long Learning, v. 19, n. 2-3, p. 247-255, 2009.

LAKOFF, G ; JOHNSON. M. Metaphors we live by. Chicago and London: The University of Chicago Press, 1980.

LARA, S.; NAVAL, C. The social-network Ning and its educative potential for fostering students' participation. Research, Reflections and Innovations in Integrating ICT in Education. Disponível em: <http://www.formatex.org/micte2009/book/11241125.pdf>. Acesso em: 10 out. 2009.

LAVE, J. Situated learning in communities of practice. In: RESNICK, L.B.; LEVIN, J.M.; TEASLEY, S.D. (Eds.). Perspective in socially shared cognition. Washington: American Psychological Association, 1991. p. 63-82.

LÉVY, P. A inteligência coletiva: por uma antropologia do ciberespaço. Trad. Luiz Paulo Rouanet. São Paulo: Loyola, 1998.

MATTE, A. C. F. Análise semiótica da sala de aula no tempo da EAD. Revista Tecnologias na Educação, v. 1, 2009. Disponível em: <http://tecnologiasnaeducacao.pro.br/revista/ a1n1/pal3.pdf $>$. Acesso em: 20 ago. 2009.

McGREAL, R. Integrated distributed learning environments (IDLEs) on the Internet: a survey. Educational Technology Review, n. 9, p. 25-31, Spring/Summer 1998.

PHAM, B. et al. Second life as a cyber learning environment for Higher Education and research collaboration. In: DISTANCE LEARNING AND INTERNET CONFERENCE 2008. Tokyo. Proceedings... p. 89-93 Disponível em: <http://www.waseda.jp/ DLI2008/program/proceedings/pdf/session4-2.pdf >. Acesso em: 10 out. 2009.

SFARD, A. On two metaphors for learning and the dangers of choosing just one. Educational Researcher, v. 27, n. 2, p. 4-13, 1998.

THOMAS, H. Learning spaces, learning environments and the dis'placement' of learning. British Journal of Educational Technology, 2009. Published online; Jun 52009 5:45AM. Disponível em: <http://www3.interscience.wiley.com/journal/120119971/issue>. 
Acesso em: 23 set. 2009.

VERNEIL, M.; BERGE, Z.L. Going online: guidelines for faculty in higher education. Educational Technology Review, v. 6, n. 3, p. 13-18, Spring/Summer 2000.

WENGER, E. Communities of practice: learning, meaning, and identity. Cambridge: Cambridge University Press, 1998.

\section{Notas}

1 Agradeço ao meu colega José Euríalo dos Reis pelas sugestões que me auxiliaram na construção deste texto.

2 Esta e todas as demais traduções são de minha responsabilidade.

3 Apesar de o termo "participação" ser aceito como metáfora na área de aprendizagem e, principalmente, na área de aquisição de segunda língua, tenho contestado seu status de metáfora. No evento realizado na Nova Zelândia, em dezembro de 2009, sobre as "metáforas da aquisição e da participação", defendi que "participação" não é uma metáfora, pois a metáfora é necessariamente um mapeamento entre, no mínimo, dois domínios (domínio-fonte e domínio-alvo). No caso da participação, não se identificam dois domínios. Mesmo entendendo que "participação" não é metáfora, continuarei a me referir à metáfora da participação por ser este um termo já consolidado.

Recebido: 06/11/2009

Aprovado: $10 / 08 / 2010$

Contato: Universidade Federal de Minas Gerais

Faculdade de Letras

Av. Antonio Carlos 6627

Pampulha

Belo Horizonte - MG

CEP $30720-290$ 